\title{
Tinea capitis in Botswana
}

This article was published in the following Dove Press journal:

Clinical, Cosmetic and Investigational Dermatology

29 January 2013

Number of times this article has been viewed

\section{Rameshwari Thakur \\ Department of Microbiology, Muzaffarnagar Medical College, Muzaffarnagar, India}

Correspondence: Rameshwari Thakur Department of Microbiology,

Muzaffarnagar Medical College, opposite Begrajpur Industrial Area, Meerut Road, Muzaffarnagar (UP) PIN-25I203, India Tel +9| 9654775082

Email rameshwari_thakur@hotmail.com
Background: Tinea capitis (TC) is a common dermatophyte infection of the scalp that can also involve the eyebrows and eyelashes.

Aim: This study aimed to find the causative fungus responsible for TC in Botswana and determine its association with the clinical types of TC.

Methods: Samples for potassium hydroxide $10 \%$ mounts and fungal cultures were collected in a microbiology laboratory at the National Health Laboratory, Gaborone, Botswana. Dermasel agar and Sabouraud dextrose agar were inoculated with the samples. Lactophenol cotton blue mounts were prepared from the culture-positive samples to study the morphological characteristics.

Results: Trichophyton violaceum was found to be the predominant causative organism of TC. Trichophyton tonsurans was isolated from one patient. Both are anthropophilic species.

Conclusion: TC was found to be most common in those aged $1-15$ years (81\%). Of 17 patients in this age group, 16 were younger than 10 years old and one was 14 years old. $T$. violaceum was the most common dermatophyte species isolated.

Keywords: Trichophyton violaceum, Trichophyton violaceum white variant, Trichophyton tonsurans, dermatophyte

\section{Introduction}

Tinea capitis (TC) is the most common dermatophyte infection in children, with the highest incidence in children aged 3-7 years old. ${ }^{1}$ This age predilection may partly result from the fungistatic properties of fatty acids in postpubertal sebum. ${ }^{2}$

Children of African descent are at increased risk of infection. ${ }^{3}$ An early diagnosis is very important, because delay in treatment can lead to superadded bacterial infection resulting in cicatrization and permanent baldness. Further, from a public health point of view, it is important to treat the infection because it is contagious. The etiological agent varies from one geographical region to another. The author previously found Trichophyton violaceum to be the most common isolate in Botswana (unpublished research) and wished to formally document this current situation in this country, as she is aware that variations and transitions of responsible organisms have been identified in other centers in other countries.

\section{Materials and methods}

From January 2009 to December 2010, 42 patients attended the dermatology clinic of the referral hospital in Gaborone with a clinical diagnosis of TC. The sample consisted of 30 children and 12 adults. The clinical types of TC varied from mild non-inflammatory scaly lesions to inflammatory TC. 
When each patient was referred to the microbiology laboratory, samples were collected after the suspected infected area was cleaned with $70 \%$ alcohol. Samples were collected from three suspicious sites ${ }^{4}$ using a scalpel blade and the wet swab method. This method was used because a simple scalp scrape alone (previously the standard method) is no longer recommended for confidently ruling out the presence of a dermatophyte. ${ }^{5}$ Potassium hydroxide $10 \%$ mounts were prepared to look for fungal elements and determine the type of hair invasion endothrix (Figure 1).

The sample collection had two limitations. First, several of the patients referred from different districts had not shampooed their hair and attended having applied petroleum jelly, which masked the clinical signs and interfered with the appropriate sample collection and processing. Second, carriers in the family were not screened: adults or children.

Lactophenol cotton blue mounts were prepared from the positive culture plates. Isolates were identified based on macroscopic and microscopic features compared with standard descriptions in mycological laboratory texts and manuals (Figures 2 and 3). ${ }^{6-9}$

\section{Results}

The majority of patients attending the microbiology department at the National Health Laboratory presented with diffuse scaly dandruff-like lesions. Two female patients in the 1-15 year old age group presented with a pustular type of TC and one with kerion. T. violaceum was found to be the predominant species $(\mathrm{n}=20[95 \%])$ and Trichophyton tonsurans was the causative organism of TC in one case (5\%). TC was most common among children aged $1-15$ years $(n=17[81 \%])-16$ of the cases in this age group were in children younger than 10 years old. In those aged 16-60 and

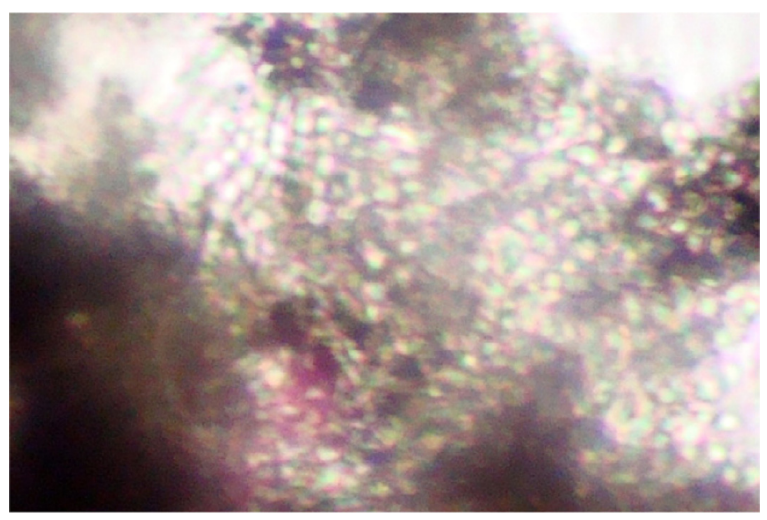

Figure I Endothrix pattern of hair invasion, with multiple spores present within the hair shaft ("bag of marbles" appearance) (potassium hydroxide 10\% mount; Magnification $\times 400$ ).

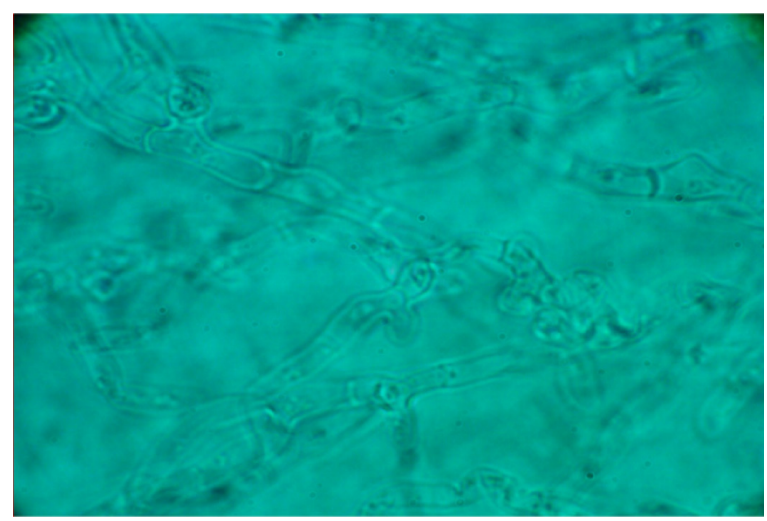

Figure 2 Trichophyton violaceum (lactophenol cotton blue mount).

Notes: Tangled hyphae, branched and irregular. No micro- or macroconidia can be seen. Magnification $\times 400$.

61-67 years old, three (14\%) and those one (5\%), respectively, were found to have TC (Table 1 and Figure 4). The distribution of the different clinical forms of TC is given in Table 2. Some subjects were found to have tinea pedis due to Trichophyton mentagrophyte.

Out of the 20 cases TC due to violet pigment-producing T. violaceum was seen in $16(80 \%)$ of the culture-positive samples (Figure 5) and the white variant of $T$. violaceum in four (20\%) (Figure 6).

\section{Discussion}

T. violaceum has been reported as the most common cause of $\mathrm{TC}$ in Libya ${ }^{10}$ and in Botswana's neighbor South Africa. In a study of 100 children (mean age of 4.6 years) in Kwa-Zulu/ Natal, dermatologists identified T. violaceum in $90 \%$ of positive cultures, making it probably the most common cause of TC in South Africa. ${ }^{11}$ T. violaceum has also been reported the most common dermatophyte in India, ${ }^{12} \mathrm{Nepal},{ }^{13}$ and Pakistan. ${ }^{14} \mathrm{TC}$ is considered rare in adults, ${ }^{15}$ but in the present study, it was identified in four adults, one of whom was a 65 -year-old female.

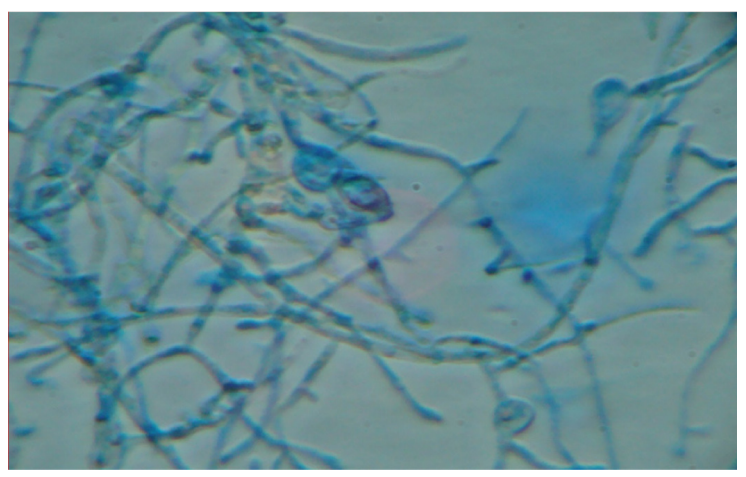

Figure 3 Trichophyton tonsurans (lactophenol cotton blue mount).

Note: Matchstick-shaped microconidia can be seen rising at right angles from the hyphae as well as beaked chlamydospores. Magnification $\times 400$. 
Table I Distribution of tinea capitis according to age group and sex

\begin{tabular}{|c|c|c|c|c|c|}
\hline Age group, years & Sex & $\begin{array}{l}\text { Dermatophytes, } \\
\text { n (\%) }\end{array}$ & $\begin{array}{l}\text { Violet pigment-producing } \\
\text { Trichophyton violaceum }\end{array}$ & $\begin{array}{l}\text { T. violaceum } \\
\text { (white variant) }\end{array}$ & $\begin{array}{l}\text { Trichophyton } \\
\text { tonsurans }\end{array}$ \\
\hline \multirow[t]{3}{*}{ Children (I-I5) } & Male & $9(43)$ & 7 & 1 & 1 \\
\hline & Female & $8(38)$ & 7 & I & \\
\hline & Total & $17(8 \mid)$ & & & \\
\hline \multirow[t]{3}{*}{ Adults (16-60) } & Male & $\mathrm{I}(5)$ & I & & \\
\hline & Female & $2(9)$ & 0 & 2 & \\
\hline & Total & $3(14)$ & & & \\
\hline \multirow[t]{3}{*}{ Older adults (6I-76) } & Male & 0 & & & \\
\hline & Female & I (5) & I & & \\
\hline & Total & I (5) & I & & \\
\hline Total cases & & 21 & & & \\
\hline
\end{tabular}

A reduction in sebum triglycerides may predispose postmenopausal women to the development of TC. ${ }^{16}$

According to one study, the prevalence of dermatophytosis was four times higher in those infected with the human immunodeficiency virus. ${ }^{17}$ This may be because manifestations may be atypical and more severe, resulting in extensive lesions, when dermatophytes infect immunocompromised patients. $^{18}$

Due to limited resources, lack of expertise, and awareness, TC can persist in the local populations of Botswana. A team of well-trained dermatologists and mycologists is needed for the right clinical and laboratory diagnosis of TC. Proper sample collection after head washing is very important for the proper clinical diagnosis and appropriate processing of samples. Since the treatment is of long duration, under- or overdiagnosis is not without complications. Diagnostic techniques must be improved by using two methods of collection and samples must be collected from at least three suspicious areas on the scalp. Asymptomatic carriage seems to be restricted to anthropophilic dermatophytes such as T. tonsurans, T. violaceum, and Microsporum audouinii. These organisms generally lack host inflammatory response and consequently mild signs of infection may escape clinical detection. ${ }^{19}$

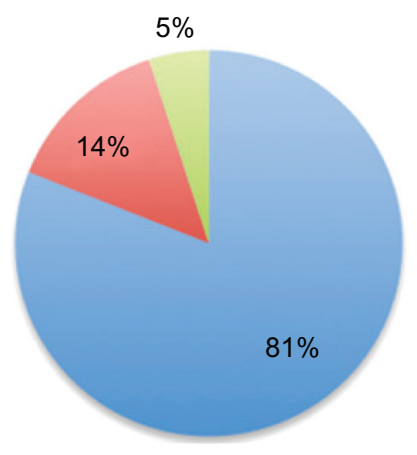

$$
\begin{aligned}
& =1-15 \text { years } \\
& -16-60 \text { years } \\
& -61-71 \text { years }
\end{aligned}
$$

Figure 4 Distribution of tinea capitis according to age group.
Table 2 Clinical types of tinea capitis identified $(n=42)$

\begin{tabular}{lll}
\hline & Cases, $\mathbf{n}$ & Percentage \\
\hline Noninflammatory & & \\
Black dot & 10 & 23.81 \\
Seborrheic dermatitis & 25 & 59.53 \\
Combined seborrheic and black dot & 4 & 9.52 \\
Inflammatory & & \\
Pustular & 2 & 4.76 \\
Kerion & 1 & 2.38 \\
\hline
\end{tabular}

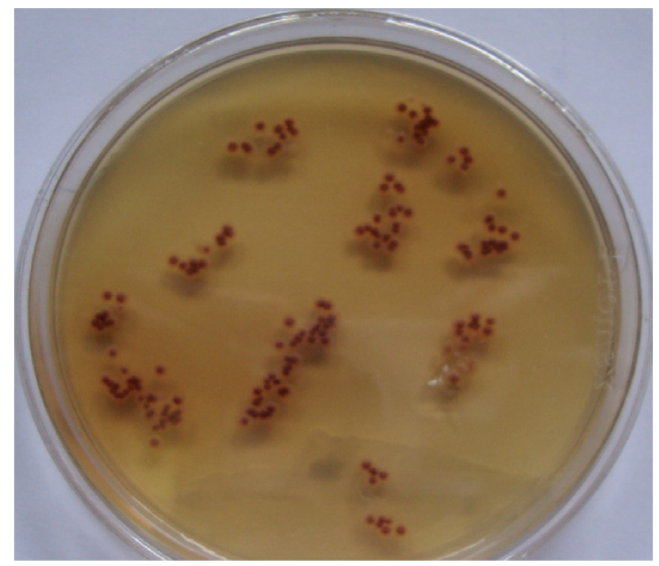

Figure 5 Violet pigment-producing Trichophyton violaceum.

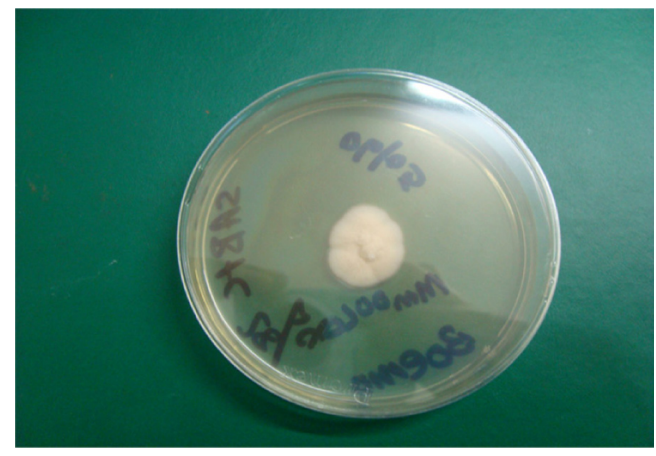

Figure 6 Trichophyton violaceum waxy colony (white variant). 
As $T$. violaceum and $T$. tonsurans are anthropophilic fungi, potential carriers should also be screened and treated once identified. Children or adults who have neither signs nor symptoms of infection, but from whose scalps causative fungi can be grown, are described as "carriers." Such asymptomatic carriers at home or at school can shed the fungus, so are potentially important sources of disease transmission. ${ }^{1,20}$ These carriers should be investigated and treated if needed. However, if there is heavy dermatophyte growth from scalp brushes taken from children with clinically normal scalps they should be treated as if they are infected - that is, with oral therapy. ${ }^{21}$

Carriers should be treated with adjunctive topical therapy. Selenium sulphide, 22 zinc pyrithione, povidone iodide, or ketconazole $^{23}$ shampoos as well as fungicidal creams or lotions ${ }^{24}$ have been shown to decrease the carriage of viable spores responsible for the disease contagion. Shampoos should be applied to scalp and hair for 5 minutes twice weekly for 2-4 weeks ${ }^{25,26}$ or three times weekly until the patient is clinically and mycologically cured. ${ }^{27}$

Some infection control measures should be observed. Brushes and combs as well as other hair accessories should be disinfected after use or discarded. ${ }^{27}$ Scissors may be placed in an instrument disinfectant - for example, for 5 minutes in a Mucocit-B (Merz Hygiene, Frankfurt, Germany) drill bath. ${ }^{24}$ Bed linen, towels, and hats should not be shared. According to some experts, school-going/day care-attending children can continue going to school or day care once treatment has been initiated with oral and topical agents although there is still a risk of infecting fellow students. ${ }^{28}$

\section{Conclusion}

T. violaceum was the most common dermatophyte species isolated in our research in Botswana. TC was most prevalent in children aged 1-15 years old, but cases were also found in adults. Due to limited resources, lack of expertise, and awareness, TC can persist in the local populations of Botswana. Doctors, nurses, and microbiology laboratory staff should be trained in the diagnosis and management of TC.

\section{Disclosure}

The author declares no conflicts of interest in this work.

\section{References}

1. Elewski BE. Tinea capitis: a current perspective. J Am Acad Dermatol. 2000;42(1 Pt 1):1-20.

2. Shy R. Tinea corporis and tinea capitis. Pediatr Rev. 2007;28(5): 164-174.

3. Hackett BC, O'Connell K, Cafferkey M, O'Donnell BF, Keane FM. Tinea capitis in a paediatric population. Ir Med J. 2006;99(10):294-295.
4. Hubbard TW, de Triquet JM. Brush-culture method for diagnosing tinea capitis. Paediatrics. 1992;90(3):416-418.

5. Akbaba M, Ilkit M, Sutoluk Z, Ates A, Zorba H. Comparison of hairbrush, toothbrush and cotton swab methods for diagnosing asymptomatic dermatophyte scalp carriage. J Eur Acad Dermatol Venereol. 2008;22(3):356-362.

6. Larone DH. Medically Important Fungi: A Guide to Identification, 3rd ed. Washington DC: American Society for Microbiology (ASM) Press; 1995:112-184.

7. Lennet EH, Balowsa A, Hausler WJ Jr, Shadomy H, editors. Manual of Clinical Microbiology, 4th ed. Washington DC: ASM Press; 1985:500-594.

8. Kwon-Chung KJ, Bennett JE. Medical Mycology, 2nd ed. Philadelphia, PA: Lea and Febige; 1992:105-170.

9. Rippon JW. Medical Mycology: The Pathogenic Fungi and Pathogenic Actinomycetes, 3rd ed. Philadelphia, PA: Saunders; 1988:169-275.

10. Ellabib MS, Agaj M, Khalifa Z, Kavanagh K. Trichophyton violaceum is the dominant cause of tinea capitis in children in Tripoli, Libya: results of a two year survey. Mycopathologia. 2001;153(3):145-147.

11. Morar N, Dlova NC, Gupta AK, Aboobaker J. Tinea capitis in Kwa-Zulu Natal, South Africa. Paediatr Dermatol. 2004;21(4):444-447.

12. Kalla G, Berga B, Solanki A, Goyal A, Batra A. Clinicomycological study of tinea capitis in desert district of Rajasthan. Indian J Dermatol Venereol Leprol. 1995;61(6):342-345.

13. Jha BN, Garg VK, Agrawal S, Khanal B, Agarwalla A. Tinea capitis in eastern Nepal. Int J Dermatol. 2006;45(2):100-102.

14. Jahangir M, Hussain I, Khurshid K, Haroon TS. A clinico-etiologic correlation in tinea capitis. Int J Dermatol. 1999;38(4):275-278.

15. Barlow D, Saxe N. Tinea capitis in adults. Int J Dermatol. 1988;27(6): 388-380.

16. Kane J, Summerbell R, Sigler L, Krajden S, Land G. Laboratory Handbook of Dermatophytes: A Clinical Guide and Laboratory Handbook of Dermatophytes and Other Filamentous Fungi from Skin, Hair, and Nails. Belmont, CA: Star; 1997.

17. Goodman DS, Teplitz ED, Wishner A, Klein RS, Burk PG, Hershenbaum E. Prevalence of cutaneous disease in patients with acquired immunodeficiency syndrome (AIDS) or AIDS-related complex. J Am Acad Dermatol. 1987;17(2 Pt 1):210-220.

18. Ray MC, Gately LE 3rd. Dermatologic manifestations of HIV infection and AIDS. Infect Dis Clin North Am. 1994;8(3):583-605.

19. Bennassar A, Grimalt R. Management of tinea capitis in childhood. Clin Cosmet Investig Dermatol. 2010;3:89-98.

20. Ilkit M, Demirhindi H. Asymptomatic dermatophyte scalp carriage: laboratory diagnosis, epidemiology and management. Mycopathologia. 2008;165(2):61-71.

21. Health Protection Agency. Tinea Capitis in the United Kingdom: A Report on its Diagnosis, Management and Prevention. London: Health Protection Agency; 2007.

22. Allen HB, Honig PJ, Leyden JJ, McGinley KJ. Selenium sulfide: adjunctive therapy for tinea capitis. Paediatrics. 1982;69(1):81-83.

23. Greer DL. Successful treatment of tinea capitis with $2 \%$ ketoconazole shampoo. Int J Dermatol. 2000;39(4):302-304.

24. Seebacher C, Abeck D, Brasch J, et al; German-Speaking Mycological Society; German Dematology Society; German Hospital Hygiene Society. Tinea capitis: ringworm of the scalp. Mycoses. 2007;50(3): 218-226.

25. Ginter-Hanselmayer G, Smolle J, Gupta A. Itraconazole in the treatment of tinea capitis caused by Microsporum canis: experience in a large cohort. Pediatr Dermatol. 2004;21(4):499-502.

26. Fuller LC, Smith CH, Cerio R, et al. A randomized comparison of 4 weeks of terbinafine vs 8 weeks of griseofulvin for the treatment of tinea capitis. Br J Dermatol. 2001;144(2):321-327.

27. Elewski BE. Treatment of tinea capitis: beyond griseofulvin. J Am Acad Dermatol. 1999;40(6 Pt 2):S27-S30.

28. Higgins EM, Fuller LC, Smith CH. Guidelines for the management of tinea capitis. British Association of Dermatologists. Br J Dermatol. 2000;143(1):53-58. 


\section{Publish your work in this journal}

Clinical, Cosmetic and Investigational Dermatology is an international, peer-reviewed, open access, online journal that focuses on the latest clinical and experimental research in all aspects of skin disease and cosmetic interventions. All areas of dermatology will be covered; contributions will be welcomed from all clinicians and basic science researchers globally. This journal is indexed on CAS. The manuscript management system is completely online and includes a very quick and fair peer-review system, which is all easy to use. Visit http://www.dovepress.com/testimonials.php to read real quotes from published authors.

Submit your manuscript here: http://www.dovepress.com/clinical-cosmetic-and-investigational-dermatology-journal 